\title{
The Influence of Different Resin Cements and Pretreatments on the Bond Strength between Zirconia and Cement
}

\begin{abstract}
T. $\mathrm{SuN}^{a}$, C. $\mathrm{HU}^{b}$, L.L. WANG ${ }^{b}$ AND L.Q. $\mathrm{SHAO}^{b, *}$
${ }^{a}$ The Medical Centre of Stomatology, the 1st Affiliated Hospital of Jinan University, Guangzhou 510630, China

${ }^{b}$ Department of Stomatology, Nanfang Hospital, Southern Medical University, Guangzhou 510515, China

The aim of this study was to analyze the influence of various luting materials and surface treatments on adhesive strength for zirconia ceramics and luting cements. The zirconia framework specimens were made into cylinders. Prior to cement, zirconia framework specimens underwent various surface treatments (sandblasting with $110 \mu \mathrm{m} \mathrm{Al} \mathrm{O}_{3}$ particles, milling with 240-grift silicon sand paper and silanization). Resin luting cement and glass ionomer luting cement were then applied on the surface of zirconia specimens. The specimens were then subjected to a shear force. The fractured surfaces were visually analyzed by scanning electron microscopy. The shear bond strength values of resin luting cement bonded to zirconia specimens were significantly higher than glass ionomer luting cement bonded to zirconia specimens $(P<0.05)$. The shear bond strength values of zirconia specimens sandblasted with $110 \mu \mathrm{m} \mathrm{Al} \mathrm{O}_{3}$ particles were significantly higher than those milled with silicon carbide papers and underwent silanization $(P<0.05)$. The shear bond strength values of zirconia specimens milled with silicon carbide papers and underwent silanization were not significantly different $(P<0.05)$. The highest shear bond strength values were achieved when the zirconia specimens were sandblasted and bonded to resin luting cement. Airborne-particle abrasion was an effective method which could enhance the bond strength of zirconia ceramics and cements. The resin luting cement exhibited a higher bond to zirconia than glass ionomer luting cement.

DOI: 10.12693 /APhysPolA.125.313
\end{abstract}

PACS: 87.85.jc

\section{Introduction}

Metal ceramic restorations have been increasingly replaced by all ceramic restorations in recent years for their superior aesthetics, inertness, and biocompatibility [1]. Yttrium oxide partially stabilized tetragonal nano zirconia polycrystal (Y-TZP) frameworks can be manufactured through $\mathrm{CAD} / \mathrm{CAM}$ process with desirable properties such as chemical and dimensional stability, high mechanical strength, and fracture-toughness. In clinical practice, zirconia ceramic can be cemented by either resin-based or non-resin-based luting cements because of the minor requirement of high retention. Nonetheless, a short-term clinical study showed that the luting cement was accounted for the loss of retention of zirconia ceramic restorations [2]. The composition of functional polymers or monomers of luting cements had an influence on the surface energies, which might change the interfacial chemical interactions and bonding potentials of zirconia restorations [3].

The popular approaches of surface treatment of zirconia include surface abrasion, application of a tribochemical silica coating, as well as silane treatment. The approaches of surface treatment for zirconia ceramics were discussed, the influence of which was not certain $[4,5]$.

The aim of this study was to analyze the influence of various luting materials and surface treatments on the adhesive strength for zirconia ceramics and luting cements.

*corresponding author; e-mail: shaolongquan@foxmail.com

\section{Material and methods}

Thirty-six Y-TZP framework specimens were fabricated and divided into six groups containing 6 specimens each (Table I). Y-TZP (Cercon Base, Densply, Hanau, Germany) blanks were milled in Cercon brain unit (Densply, Hanau, Germany) then sintered in Cercon heat furnace (Densply, Hanau, Germany). The zirconia framework specimens of each group were made into cylinders (5.0 $\mathrm{mm}$ in diameter and $3.0 \mathrm{~mm}$ in height) using a metal mold. Prior to cement, zirconia framework specimens underwent different surface treatments (sandblasting with $110 \mu \mathrm{m} \mathrm{Al} \mathrm{O}_{3} \mathrm{O}_{3}$ particles, milling with 240-grift silicon sand paper and silanization). Resin luting cement (Panavia F, Kuraray Medical, Osaka, Japan) and glass ionomer luting cement (Fuji 9, Fuji CEM, Tokyo, Japan) were then applied on the surface of zirconia framework specimens. The resin luting material was applied on zirconia surface with a seating pressure of $1 \mathrm{~kg}$ maintained over the specimens during the first 5 min of cement autocure. The resin cement cylinder was light polymerized for $20 \mathrm{~s}$.

Each specimen was mounted in a metal holder on the universal testing machine (AG-IC, Shimadzu, Kyoto, Japan). Load was applied at a crosshead speed of $1 \mathrm{~mm} / \mathrm{min}$ until failure. The ultimate load to failure was recorded by the system's software (Trapezium X, Shimadzu, Kyoto, Japan).

The fractured surfaces were visually analyzed with a SEM (SSX-550, SHIMADZU, Kyoto, Japan).

The data was statistically analyzed $(\alpha=0.05)$ by the SPSS 13.0 Program (SPSS Inc. Chicago, USA). 


\section{Results}

The SEM view of the fractured interface of zirconia specimens milled with sand papers showed a rough surface with scratches (Fig. 1). Figure 2 demonstrated the fractured interface of the sandblasted zirconia specimens was the roughest. Figure 3 demonstrated a relatively smoother surface for zirconia specimens underwent silanization.

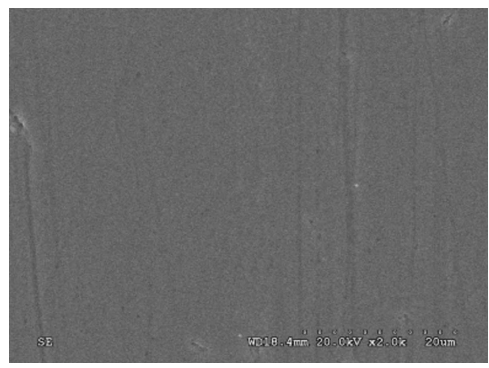

Fig. 1. The fractured interface of zirconia frameworks milled with sand paper.

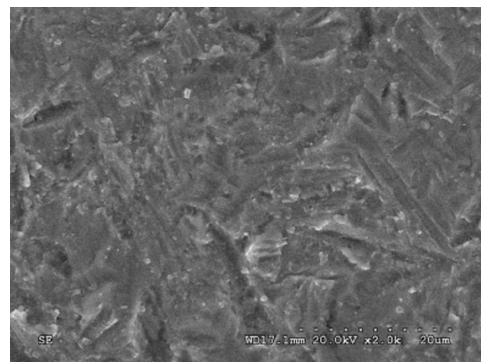

Fig. 2. The fractured interface of the sandblasted zirconia frameworks.

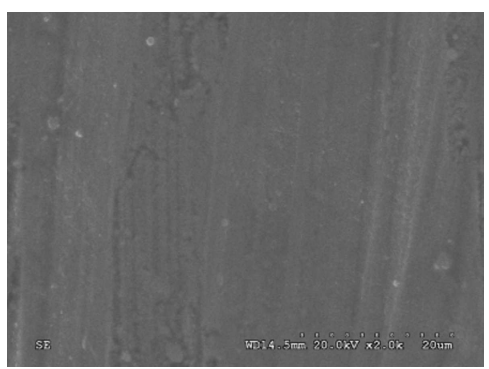

Fig. 3. The fractured interface of the zirconia frameworks underwent silanization.

$2 \times 3$ factorial experiment design of six groups of zirconia specimens and the mean shear bond strength (SBS) values were shown in Table I. $2 \times 3$ factorial design ANOVA of zirconia specimens underwent various surface treatments and luting cements was shown in Table II. The SBS values of resin luting cement bonded to zirconia frameworks were significantly higher than glass ionomer luting cement bonded to zirconia frameworks $(P<0.05)$. The SBS values of zirconia specimens un-
TABLE I

$2 \times 3$ factorial experiment design of six groups of zirconia specimens and the mean SBS values.

\begin{tabular}{c|c|c|c}
\hline \hline Group & Luting cement & Surface treatment & SBS [MPa] \\
\hline 1 & resin luting cement & sand paper milling & $25.00 \pm 3.41$ \\
2 & resin luting cement & sand blasting & $33.68 \pm 2.77$ \\
3 & resin luting cement & silanization & $24.69 \pm 2.31$ \\
4 & glass ionomer luting cement & sand paper milling & $18.01 \pm 1.96$ \\
5 & glass ionomer luting cement & sand blasting & $21.32 \pm 2.18$ \\
6 & glass ionomer luting cement & silanization & $18.02 \pm 2.01$
\end{tabular}

TABLE III

SNK multiple comparisons of surface treatments.

\begin{tabular}{c|c|c|c}
\hline \hline \multirow{2}{*}{ Surface treatment } & \multirow{2}{*}{$N$} & \multicolumn{2}{|c}{ Subset } \\
\cline { 3 - 4 } & & 1 & 2 \\
\hline silanization & 12 & 21.35667 & \\
sand paper milling & 12 & 21.505000 & \\
sand blasting & 12 & & 27.500000 \\
$P$ & & 0.885 & 1.000
\end{tabular}

derwent various surface treatments were significantly different $(P<0.05)$. SNK multiple comparisons of surface treatments were shown in Table III. The SBS values of zirconia specimens sandblasted with $\mathrm{Al}_{2} \mathrm{O}_{3}$ particles were significantly higher than those milled with silicon carbide papers and underwent silanization $(P<0.05)$. The SBS values of zirconia specimens milled with silicon carbide papers and underwent silanization were not significantly different $(P<0.05)$.

There was crossover effect between the two independent variables $(P<0.05)$. The highest SBS values were achieved when zirconia frameworks were sandblasted and bonded to resin luting cement.

\section{Discussion}

Although zirconia framework materials were proved to exhibit optimum mechanical strength, their successful rates also depended on the establishment of a reliable bond with the luting agent [6]. Shear bond strength testing can be used as general baseline and a clinically more relevant bonding area. Surface abrasion or roughening might establish adhesion through micro mechanical retention. HF etching was reported to be inadequate for enhancement of bond strength between zirconia ceramics and cements because of the resistant to acid etching of zirconia [7]. The influence of HF etching on bond strength was consequently not included in this study.

The SEM view of the fractured interface of zirconia specimens milled with sand papers showed a rough surface with scratches (Fig. 1). Milling with sand papers might not be sufficient to promote adhesion. Meanwhile, the scratches and subcritical microcracks generated from milling has the possibility to create phase transformation within the zirconia surface, consequently causing unfavorable changes of superior mechanical properties of zirconia ceramics [8]. Figure 2 demonstrated the fractured interface of the sandblasted zirconia specimens was the roughest. Tables I-III showing airborne-particle abrasion was an effective treatment which could enhance the bond strength of zirconia and cements. $\mathrm{Al}_{2} \mathrm{O}_{3}$ 
airborne-particle abrasion has been widely used on zirconia. It was reported to increase the surface energy, surface area for bonding, and wettability [9]. Moreover, it has been demonstrated that, besides increasing surface roughness of zirconia ceramics, air abrasion also leads to the transformation from monoclinic to tetragonal phase which was usually accompanied by an increased flexural strength [10]. Figure 3 demonstrated a relatively smoother surface for zirconia specimens underwent silanization. Tables I-III showing the SBS values of zirconia specimens milled with silicon carbide papers and underwent silanization were not significantly different $(P<0.05)$, indicating the smooth surface might not be sufficient to promote adhesion. For promotion of micromechanical retention, sandblasting was recommended instead of acid etching, and silane coupling agents because the silane coupling agent was inadequate to improve the bond strength between zirconia and resin cements for the lack of silica of zirconia [7].

\section{TABLE II}

$2 \times 3$ Factorial design ANOVA of zirconia specimens underwent various surface treatments and luting cements.

\begin{tabular}{c|c|c|c|c|c}
\hline \hline Source & $\begin{array}{c}\text { Type III sum } \\
\text { of squares }\end{array}$ & $v$ & $\begin{array}{c}\text { Mean } \\
\text { square }\end{array}$ & $F$ & $P$ \\
\hline sort of cement & 676.867 & 1 & 676.867 & 108.999 & 0.000 \\
surface treatment & 294.810 & 2 & 147.405 & 23.737 & 0.000 \\
cement ${ }^{*}$ surface treatment & 61.355 & 2 & 30.678 & 4.940 & 0.014 \\
error & 186.296 & 30 & 6.210 & & \\
corrected total & 1219.329 & 35 & & &
\end{tabular}

Tables I-II showed that the SBS values of resin luting cement bonded to zirconia specimens were significantly higher than glass ionomer luting cement $(P<0.05)$. It might be attributed to the lower mechanical properties of glass ionomers. It was reported that compressive and flexural strengths of resin-modified glass ionomer are considerably lower than those of resin cement [11]. Son et al. [12] reported a lower shear bond strength of the resin-modified glass ionomer bonded to zirconia than resin luting cement. Glass ionomer showed irregular cracks after shear and fatigue test. While, resin luting cements featured high elastic moduli and low elastic limits.

Table III showed that there was crossover effect between the two independent variables $(P<0.05)$. The highest SBS values were consequently achieved when zirconia underwent sandblasting and applied with resin luting cement.

\section{Conclusions}

Airborne-particle abrasion was an effective method for enhancement for bond strength of zirconia and cements. The resin luting cements exhibited a higher bond to zirconia than glass ionomer cement. Higher bond strength was achieved when zirconia frameworks underwent sandblasted and bonded to resin luting cement. For promotion of micromechanical retention for zirconia ceramics, the applications of sandblasting and resin luting cement was recommended.

\section{Acknowledgments}

This work was supported by Scientific Cultivation Foundation of the 1st Affiliated Hospital of Jinan Uni- versity (2013205), Natural Science Foundation of Guangdong Province (9151051501000072), National Natural Science Foundation (31070857) and Special Project on the Integration of Industry, Education and Research of Guangdong Province (2012B091000147).

\section{References}

[1] T. Derand, M. Molin, K. Kvam, Dent. Mater. 21, 1158 (2005).

[2] M. Rosentritt, D. Steiger, M. Behr, G. Handel, C. Kolbeck, J. Dent. 37, 978 (2009).

[3] E. Asmussen, A. Peutzfeldt, Dent. Mater. 21, 1039 (2005).

[4] H. Yamaguchi, S. Ino, N. Hamano, S. Okada, T. Teranaka, Dent. Mater. J. 31, 472 (2012).

[5] J.R. Queiroz, P. Benetti, M. Massi, L.N. Junior, A. Della Bona, Dent. Mater. 28, 763 (2012).

[6] V.C. Bachhav, M.A. Aras, Quintessence Int. 42, 173 (2011).

[7] G.A. Borges, A.M. Sophr, M.F. de Goes, L.C. Sobrinho, D.C. Chan, J. Prosthet. Dent. 89, 479 (2003).

[8] A. Sundh, G. Sjögren, Dent. Mater. 22, 778 (2006).

[9] A. Della Bona, M. Borba, P. Benetti, D. Cecchetti, Braz. Oral. Res. 21, 10 (2007).

[10] S. Karakoca, H. Yilmaz, J. Biomed. Mater. Res. B Appl. Biomater. 91, 930 (2009).

[11] C.J. Kleverlaan, R.N. van Duinen, A.J. Feilzer, Dent. Mater. 20, 45 (2004).

[12] Y.H. Son, C.H. Han, S. Kim, J. Dent. 40, 866 (2012). 